\title{
Self-Reported ADHD Symptoms Prevalence in a University Student Population: Using Adult Self-Report-V1.1 Screener
}

\author{
N. M. Bakhshani ${ }^{1}$, S. Babaei $^{2} \&$ M. Raghibi ${ }^{3}$ \\ ${ }^{1}$ Research Center for Children and adolescents Health, Department of Clinical Psychology, Zahedan University \\ of Medical Sciences, Zahedan, Iran \\ ${ }^{2}$ University of Medical Sciences, Zahedan, Iran \\ ${ }^{3}$ Department of Psychology, Faculty of Education and Psychology, Sistan and Baluchestan University, Zahedan, \\ Iran
}

Correspondence: Samaneh Babaei, University of Medical Sciences, PO box 9819713955, Zahedan, Iran. Tel: 98-54-1452-2637. E-mail: smnhbabaei3@gmail.com

Received: June 14, 2012 Accepted: July 23, $2012 \quad$ Online Published: July 28, 2012

doi:10.5539/mas.v6n8p63 URL: http://dx.doi.org/10.5539/mas.v6n8p63

\begin{abstract}
The aim of this study was to examine the prevalence of adult' $s$ attention deficit/hyperactivity symptoms among the University students in Iran. This descriptive-analytical study conducted on 403 University students of Sistan and Baluchestan in second half of the educational year of 2010-2011. For gathering the data we used Adler, Kessler-Spenser Hyperactivity Questionnaire. All participants were asked to complete the Adult Self-Report Scale-V1,1 (ASRS-VI.I). Findings: Considering the subscale of attention- deficit, the results indicated that 104 (25.1\%) of participants had symptoms of ADHD and about 47 (11.3\%) reported attention deficit, 43 (10.3\%) hyperactivity/impulsivity and 14 (3.4\%) combine symptoms. Conclusion: according to the results, it seems that the symptoms of hyperactivity and attention-deficit are prevalent and common among the university students. Therefore, more evaluation and further studies as well as providing preventive and treatment plans to avoid the educational problems and to prevent risky behaviors like drug abuse are recommended.
\end{abstract}

Keywords: prevalence, attention deficit/hyperactivity disorder, adult ADHD, students

\section{Introduction}

ADHD-Attention deficit / hyperactivity disorder is a neuropsychological disorder, which is prevalent all around the world among children and adolescents (Faraone \& Biederman, 1998). It is estimated that 3-5\% children suffer from that (Clarren \& Smith, 1978), this disorder appears with improper levels of attention deficit, hyperactivity and impulsivity (Association \& DSM-IV., 2000; Dadsetan, 2008). Although it most often diagnosed as a childhood disorder, but recent studies indicated that in $60 \%$ of cases, symptoms of ADHD continue till the periods of adolescent and adulthood (Fowler et al., 2006; Valdizan \& Izaguerri-Gracia, 2009). Nevertheless, it has been rarely recognized in adults (Wender \& Garfinkel, 1989). The symptoms of ADHD, although, are similar in different age groups but in adults are not as apparent as in children. Thus, these symptoms may not be considered as definite signs of ADHD in adults (Schoenstadt, 2008). However, some features including hyperactivity, attention deficit, severe emotional response, low threshold of stimulation, sudden anger, poor social relationship, educational and occupational failure, alcohol abuse, time managing problems in friendly relations, financial problems, tendency to disrupt others' speech, can help us to recognize the ADHD patients (Low, 2009; Teeter, 2000; Wender \& Garfinkel, 1989; Wilens, Faraone, \& Biederman, 2004). In generally, it has been reported that 2-7 percent of adults suffer from ADHD (Alizadeh, 2006; Arabgol, Hayati, \& Hadid, 2005; Kaplan \& Sadock, 1988; Kessler et al., 2006; Valdizan \& Izaguerri-Gracia, 2009). Negative effects of this disorder are associated with drug abuse, alcohol consumption, smoking, traffic accidents. We believe to prevent educational failure and other problems associated with ADHD, screening ADHD and associated symptoms in student is a necessity (Martin, Volkmar, \& Lewis, 2007). Thus, this study was designed for examining the prevalence rate of ADHD symptoms among the students of Sistan\&Baluchestan University. 


\section{Patients and Methods}

This cross-sectional study was performed in the second half of academic year 2010-2011 on 403 students of Sistan and Baluchestan University who were selected through non-randomly sampling. The participants were asked to complete the Adult Self-Report Scale-V1.1 (ASRS-V1, 1) if they are willing to. ASRS-V 1, 1, is a valid and reliable self-report Scale (Adler et al., 2006). It's internal consistency is high (Cronbach's Alpha, 0.88, 0.89 for patient and rater-administered versions respectively). This scale has two parts: Part A and Part B. The Part A consists of 6 questions and Part B is composed of 12 questions. Part A is performed as a screener tool for Adult ADHD. Positive response to at least 4 questions of the part A is necessary to recognize possible ADHD. So that response to the first 3 questions must be in range of "sometimes" to "very often" and to questions of 4-6 must be "often" or "very often". In current Study, the Part B of ASRS (questions 7-18 of full ASRS), was used to identify the subtypes of ADHD symptom. Using SPSS 16, the data were analyzed.

\section{Results}

The study involved 403 university students aged 17-34 year. Presented in Table 1 are frequencies of participants according to gender and age; one can see that $49.8 \%$ of participants are female and $50.2 \%$ are male. Two hundred and thirty eight (58.9\%) of the participant were aged 17-22, 149 (36.9\%) and 17(14.2\%) respectively were aged 23-38 and 29-34 years.

Table 1. The demographic characteristics of participants in the study

\begin{tabular}{llcc}
\hline \multirow{3}{*}{ Gender } & & $\mathrm{n}$ & $\%$ \\
\cline { 2 - 4 } & Female & 201 & 49.8 \\
\multirow{3}{*}{ Age } & Male & 203 & 50.2 \\
& $\mathbf{1 7 - 2 2}$ & 238 & 58.9 \\
& $\mathbf{2 3 - 2 8}$ & 149 & 36.9 \\
& $\mathbf{2 9 - 3 4}$ & 17 & 4.2 \\
\hline
\end{tabular}

Table 2 shows the severity of ADHD symptoms (Part A) based on gender of participants, according of test results there are no different between mean scores of female and male students in attention deficit and hyperactivity/impulsivity subscales.

Table 2. Comparison of symptoms severity of attention-deficit and hyperactivity/impulsivity (based on Scores of Part A)

\begin{tabular}{|c|c|c|c|c|}
\hline \multirow{3}{*}{$\begin{array}{l}\text { Index } \\
\text { Gender } \\
\text { Male }\end{array}$} & \multicolumn{2}{|c|}{ Attention Deficit } & \multicolumn{2}{|c|}{ Hyperactivity/Impulsivity } \\
\hline & \multicolumn{2}{|c|}{ Mean \pm Sd } & \multicolumn{2}{|c|}{ Mean \pm Sd } \\
\hline & 2.68 & 2.111 & 1.48 & 0.77 \\
\hline Female & 2.75 & 2.109 & 1.43 & 0.76 \\
\hline $\mathbf{t}$ & \multicolumn{2}{|c|}{-0.371} & \multicolumn{2}{|c|}{0.689} \\
\hline $\mathbf{p}$ & \multicolumn{2}{|c|}{0.71} & \multicolumn{2}{|c|}{0.49} \\
\hline
\end{tabular}

As the Table 3 shows, the prevalence of ADHD symptoms among participants was $25.1 \%$, and about $11.3 \%$ reported attention deficit, $10.3 \%$ hyperactivity/impulsivity and $3.4 \%$ combine symptoms. 
Table 3. Distribution of symptoms by types of ADHD among participants

\begin{tabular}{lcc}
\hline Types of ADHD & & \\
\cline { 2 - 3 } & $\mathrm{n}$ & $\%$ \\
\hline Attention deficit & 47 & 11.3 \\
Hyperactivity/Impulsivity & 43 & 10.3 \\
Combine & 14 & 3.4 \\
Total & 104 & 25.1 \\
\hline
\end{tabular}

Table 4 shows the distribution of self-reported ADHD symptoms with gender and age variables. Frequency of attention deficit (53.2\% vs. $46.8 \%)$ and combine types (57.1\% vs. $42.9 \%)$ are higher in male student than female ones, also among 17-22 age group attention deficit and Hyperactivity/ Impulsivity's are most prevalent. However the prevalence rate of ADHD Symptoms reported by 29-34 years student is lowest.

Table 4. Prevalence of types of ADHD among participants by gender and age groups

\begin{tabular}{cccccccc}
\hline & & \multicolumn{2}{c}{ Attention deficit } & \multicolumn{2}{c}{ Hyperactivity/impulsivity } & \multicolumn{2}{c}{ Combine } \\
\cline { 3 - 8 } & & $\mathbf{n}$ & $\mathbf{\%}$ & $\mathbf{n}$ & $\mathbf{\%}$ & $\mathbf{n}$ & $\mathbf{\%}$ \\
\hline \multirow{4}{*}{ Gender } & Male & 25 & 53.2 & 20 & 46.5 & 8 & 57.1 \\
& Female & 22 & 46.8 & 23 & 53.5 & 6 & 42.9 \\
& $17-22$ & 25 & 53.2 & 25 & 58.1 & 7 & 50 \\
& $23-28$ & 20 & 42.6 & 18 & 41.9 & 7 & 50 \\
& $29-34$ & 1 & 2.1 & 0 & 0 & 0 & 0 \\
\hline
\end{tabular}

\section{Discussion}

The results of current study, using the WHO ASRSV1.1 screener, indicated a self-reported ADHD Symptoms Prevalence rate of is $25.1 \%$. Whereas joining to governmental universities in Iran is difficult; it is assumed that prevalence of ADHD symptoms would be lower than general populations. As far as we know, there is no data on Adult's ADHD symptom prevalence in our country to compare the findings of the study, but the prevalence rate of ADHD in our study is much higher than those reported in general populations (Polanczyk, de Lima, Horta, Biederman, \& Rohde, 2007) and University Students (DuPaul et al., 2001; DuPaul, Weyandt, O’Dell, \& Varejao, 2009; Weyandt, Linterman, \& Rice, 1995) in the other countries.

Due to findings of the study youngest age groups, reported higher symptoms prevalence rates than the oldest age groups, that is consistent with findings of (Atwoli, Owiti, Manguro, \& Ndambuki, 2011; Hill \& Schoener, 1996). Moreover, according to the results of full ASRS Screener the attention deficit type (11.3\%) of ADHD was more prevalent than Hyperactivity/Impulsivity type (10.3\%) and combine type (3.4\%). This finding is consistent with the findings of other studies (Heiligenstein, Conyers, Berns, \& Miller, 1998; Rostain \& Ramsay, 2006). No using of clinical assessment to evaluate the results of the ASRS Screener was one of the limitations of current study that may have caused to a higher prevalence rate of ADHD symptoms. In addition high prevalence rates of ADHD symptoms may be a result of limitation of DSM-IV criteria (Barkley, Murphy, \& Fischer, 2010) and the scales developed based on its criteria, or feigning and exaggerating ADHD symptoms by college students (Jasinski et al., 2011; Lee Booksh, Pella, Singh, \& Drew Gouvier, 2010; Sollman, Ranseen, \& Berry, 2010). Kessler et al. (2006) found that Adult ADHD is co- morbid with other mental disorders such as mood disorder, Anxiety disorder, substance use disorder and impulsive control disorder. Moreover, students with ADHD have low self-esteem and deficit in social skills (Kessler et al., 2006; Seidman, Biederman, Weber, Hatch, \& Faraone, 1998). Individuals with ADHD, also, abuse alcohol, and drugs. Using alcohol (Mannuzza, Klein, Bessler, Malloy, \& LaPadula, 1993) and Marijuana (Pope \& Yurgelun-Todd, 1996) are associated with cognitive deficit and low academic achievement. Thus specific interventions must be used for reducing ADHD symptoms and negative effects on academic functions and adjustment of students. Rostain and Ramsay (2007) suggested 4 types of effective interventions that are: Academic Support, Coaching, Pharmacotherapy and CBT. 
Taken together university students face to a variety of academic tasks and assignment required high attention and concentration capacity, high planning ability and social skills to manage appropriately. In general, hidden disorders such as ADHD have negative effects on executive function and increases rate of academic failure (Wolf, 2001). Thus providing preventive, therapeutic and supportive systems for college students is a necessity.

\section{Acknowledgement}

We are deeply thankful to all the participants who voluntary cooperated with this research.

\section{References}

Alizadeh, H. (2006). Theoretical explanation of Attention deficit/ Hyperactivity disorder: (Pattern of behavioral inhibition and self-control nature). Res. Q Except Child, 3(4).

Arabgol, F., Hayati, M., \& Hadid, m. (2005). The Prevalence of adulthood attention deficit / hyperactivity symptoms in students. Advances In Cognitive Science, 6(1-2), 73-77.

Association, A. P., \& DSM-IV., A. P. A. T. F. o. (2000). Diagnostic and statistical manual of mental disorders: $D S M-I V-T R$. American Psychiatric Publishing, Inc.

Atwoli, L., Owiti, P., Manguro, G., \& Ndambuki, D. (2011). Attention deficit hyperactivity disorder symptom self-report among medical students in Eldoret, Kenya. Afr. J. Psychiatry (Johannesbg), 14(4), 286-289.

Barkley, R. A., Murphy, K. R., \& Fischer, M. (2010). ADHD in adults: What the science says. The Guilford Press.

Clarren, S. K., \& Smith, D. W. (1978). The fetal alcohol syndrome. New England J. Med, 298(19), 1063-1067. http://dx.doi.org/10.1056/NEJM197805112981906

Dadsetan, P. A. (2008). Developmental Psychopathology from Childhood to Adulthood (2 ed.). Tehran: Samt Publication.

DuPaul, G. J., Schaughency, E. A., Weyandt, L. L., Tripp, G., Kiesner, J., Ota, K., \& Stanish, H. (2001). Self-report of ADHD symptoms in university students: cross-gender and cross-national prevalence. J. Learn Disabil, 34(4), 370-379. http://dx.doi.org/10.1177/002221940103400412

DuPaul, G. J., Weyandt, L. L., O’Dell, S. M., \& Varejao, M. (2009). College students with ADHD: current status and future directions. J. Atten. Disord., 13(3), 234-250. http://dx.doi.org/10.1177/1087054709340650

Faraone, S. V., \& Biederman, J. (1998). Neurobiology of attention-deficit hyperactivity disorder. Biol. Psychiatry, 44(10), 951-958. http://dx.doi.org/10.1016/S0006-3223(98)00240-6

Fowler, M. (1991). Attention deficit disorder. National information center for children and youth with disabilities (NICHCY). Washington DC, 20013-1492.

Heiligenstein, E., Conyers, L. M., Berns, A. R., \& Miller, M. A. (1998). Preliminary normative data on DSM-IV attention deficit hyperactivity disorder in college students. J. Am. Coll Health, 46(4), 185-188. http://dx.doi.org/10.1080/07448489809595609

Hill, J. C., \& Schoener, E. P. (1996). Age-dependent decline of attention deficit hyperactivity disorder. Am. J. Psychiatry, 153(9), 1143-1146.

Jasinski, L. J., Harp, J. P., Berry, D. T., Shandera-Ochsner, A. L., Mason, L. H., \& Ranseen, J. D. (2011). Using symptom validity tests to detect malingered ADHD in college students. Clin. Neuropsychol, 25(8), 1415-1428. http://dx.doi.org/10.1080/13854046.2011.630024

Kaplan, H. I., \& Sadock, B. J. (1988). Synopsis of psychiatry: Behavioral sciences clinical psychiatry. Williams $\&$ Wilkins Co.

Kessler, R. C., Adler, L., Barkley, R., Biederman, J., Conners, C. K., Demler, O., ... Zaslavsky, A. M. (2006). The prevalence and correlates of adult ADHD in the United States: results from the National Comorbidity Survey Replication. The American journal of psychiatry, 163(4), 716. http://dx.doi.org/10.1176/appi.ajp.163.4.716

Lee Booksh, R., Pella, R. D., Singh, A. N., \& Drew Gouvier, W. (2010). Ability of college students to simulate ADHD on objective measures of attention. J. Atten. Disord., 13(4), 325-338. http://dx.doi.org/10.1177/1087054708329927

Low, K. (2009). Prevalence Rates of ADHD How Common Is ADHD? About. com Guide. 
Mannuzza, S., Klein, R. G., Bessler, A., Malloy, P., \& LaPadula, M. (1993). Adult outcome of hyperactive boys: educational achievement, occupational rank, and psychiatric status. Arch. Gen. Psychiatry, 50(7), 565. http://dx.doi.org/10.1001/archpsyc.1993.01820190067007

Martin, A., Volkmar, F. R., \& Lewis, M. (2007). Lewis's child and adolescent psychiatry: a comprehensive textbook. Lippincott Williams \& Wilkins.

Polanczyk, G., de Lima, M. S., Horta, B. L., Biederman, J., \& Rohde, L. A. (2007). The worldwide prevalence of ADHD: a systematic review and metaregression analysis. Am. J. Psychiatry, 164(6), 942-948. http://dx.doi.org/10.1176/appi.ajp.164.6.942

Pope, H. G., Jr., M. D., \& Yurgelun-Todd, D. (1996). The residual cognitive effects of heavy marijuana use in college students. JAMA, 275(7), 521-527. http://dx.doi.org/10.1001/jama.275.7.521

Rostain, A. L., \& Ramsay, J. R. (2006). College Students with Attention-Deficit Hyperactivity Disorder. New Directions in Assessment and Treatment. Monograph American College Health Association. Retrieved from http://www.centerforautismresearch.com/our_team/details/?cat=1\&id=6

Rostain, A. L., \& Ramsay, J. R. (2007). College and High School Students with Attention-Deficit/Hyperactivity Disorder: New Directions in Assessment and Treatment. ACHA Prof Dev Program, 7-16.

Schoenstadt, A. (2008). Adult ADHD to Albuterol Solution. eMedTV Sitemap.

Seidman, L. J., Biederman, J., Weber, W., Hatch, M., \& Faraone, S. V. (1998). Neuropsychological function in adults with attention-deficit hyperactivity disorder. Biol. Psychiatry, 44(4), 260-268. http://dx.doi.org/10.1016/S0006-3223(97)00392-2

Sollman, M. J., Ranseen, J. D., \& Berry, D. T. (2010). Detection of feigned ADHD in college students. Psychol. Assess, 22(2), 325-335. http://dx.doi.org/10.1037/a0018857

Teeter, P. A. (2000). Interventions for ADHD: Treatment in developmental context: The Guilford Press.

Valdizan, J. R., \& Izaguerri-Gracia, A. C. (2009). [Attention deficit hyperactivity disorder in adults]. Rev Neurol, 48 Suppl 2, S95-99.

Wender, P. H., \& Garfinkel, B. D. (1989). Attention-deficit hyperactivity disorder: Adult manifestations. In Sadock, H. I. \& Kaplan, B. J. (Eds.), Compr Textbook Psychiatry. Baltimore: Williams \& Wilkins.

Weyandt, L. L., Linterman, I., \& Rice, J. A. (1995). Reported prevalence of attentional difficulties in a general sample of college students. J. Psychopathol. Behav. Assess, 17(3), 293-304. http://dx.doi.org/10.1007/BF02229304

Wilens, T. E., Faraone, S. V., \& Biederman, J. (2004). Attention-deficit/hyperactivity disorder in adults. [Research Support, U.S. Gov't, P.H.S.]. JAMA, 292(5), 619-623. http://dx.doi.org/10.1001/jama.292.5.619

Wolf, L. E. (2001). College students with ADHD and other hidden disabilities. Outcomes and interventions. Ann. N. Y. Acad. Sci., 931, 385-395. http://dx.doi.org/10.1111/j.1749-6632.2001.tb05792.x 